\title{
Efficacy and safety of dezocine in postoperative pain relief: Systematic review and Meta-analysis
}

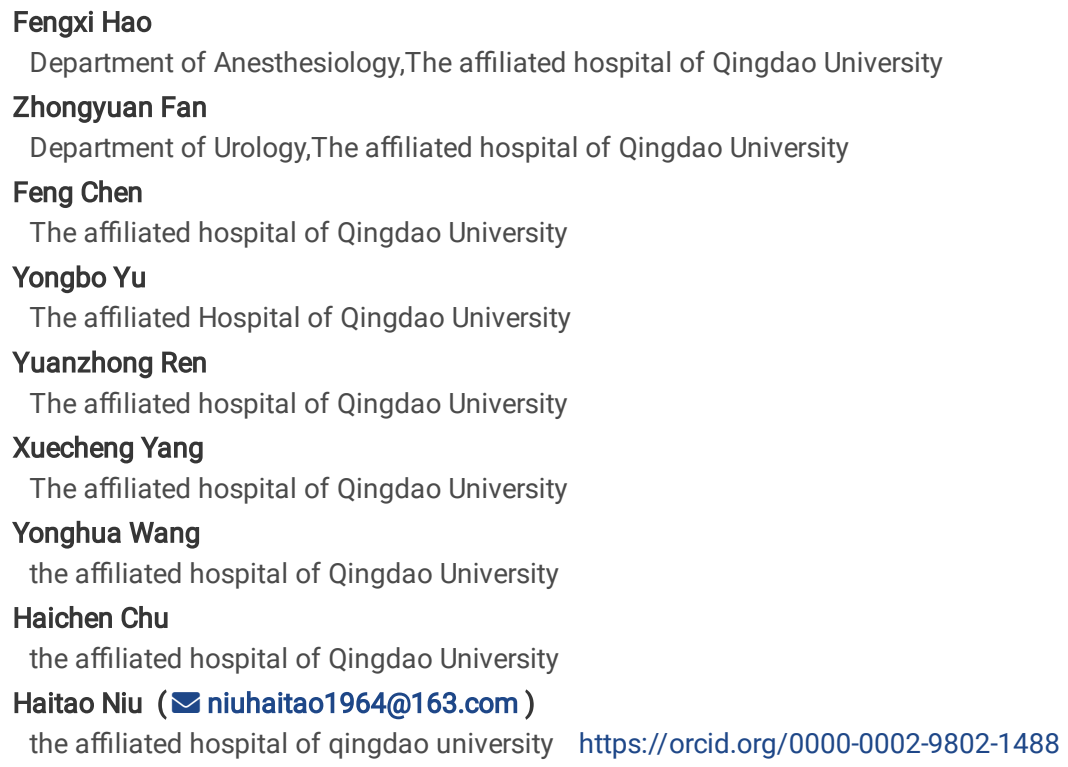




\section{Abstract}

Objective: To systematically evaluate the efficacy index and adverse reactions of dezocine in postoperative pain relief, provide statistical theoretical support for guiding clinical application. Methods: We extracted and analyzed multiple data of patients from the PubMed, Embase, The Cochrane Library and China National Knowledge Infrastructure (CNKI) for use in randomized controlled trials of various surgical postoperative pain relief. We used meta-analysis to study several measures of efficacy and safety of dezocine, including visual analogue score (VAS), Ramsay sedation score, mean arterial pressure (MAP), heart rate (HR), Pulse Oxygen Saturation (Sp02) and the incidence of adverse events(AEs). The material data were calculated and analyzed using Review Manager 5.3. Results: After exclusion of literature that did not meet the inclusion criteria, our analysis included 14 randomized controlled trials. The Mean Difference (MD) of VAS at $1 \mathrm{~h} / 6 \mathrm{~h} / 24 \mathrm{~h}$ between the dezocine group and the placebo group was $-1.37(95 \% \mathrm{Cl}-2.07,-0.67, \mathrm{P}=0.0001) \rrbracket-0.52(95 \% \mathrm{Cl}-1.04,0.01, \mathrm{P}=0.05) \rrbracket-0.10$ $(95 \% \mathrm{Cl}-0.39,0.20, \mathrm{P}=0.52)$, respectively. The $\mathrm{MD}$ of Ramsay sedation score at $2 \mathrm{~h} / 8 \mathrm{~h}$ was $1.21(95 \% \mathrm{Cl} 0.67,1.75, \mathrm{P} \llbracket 0.0001)$ and $-0.17(95 \% \mathrm{Cl}-0.59,0.26$, $\mathrm{P}=0.44)$. The MD of MAP at T0/T1/T2 was $-0.28(95 \% \mathrm{Cl}-2.46,1.89, \mathrm{P}=0.80) \bigotimes-2.66(95 \% \mathrm{Cl}-5.07,-0.25, \mathrm{P}=0.03) \rrbracket-4.53(95 \% \mathrm{Cl}-6.17,-2.89, \mathrm{P} \otimes 0.00001)$. The MD of $\mathrm{HR}$ at T0/T1/T2 was $-2.26(95 \% \mathrm{Cl}-4.32,-0.21, \mathrm{P}=0.03) \varangle-3.58(95 \% \mathrm{Cl}-5.21,-1.96, \mathrm{P} \otimes 0.0001),-3.75(95 \% \mathrm{Cl}-11.55,4.04, \mathrm{P}=0.35)$. The MD of SpO2 at T0/T1 was $-0.90(95 \% \mathrm{Cl}-1.77,-0.03, \mathrm{P}=0.04)$ and $0.36(95 \% \mathrm{Cl} 0.02,0.71, \mathrm{P}=0.04)$. The odds ratio (OR) of AEs was $0.53(95 \% \mathrm{Cl} 0.39,0.71, \mathrm{P} \otimes 0.0001)$. Conclusion: Dezocine shows appropriate anesthetic efficacy and fewer adverse effects, which can reduce postoperative pain effectively.

\section{Background}

Opioids are the main drugs for postoperative analgesia, but patients with long-term opioids are difficult to obtain optimal postoperative analgesia due to tolerance to opioids, and cause some unavoidable adverse reactions. ${ }^{[1]}$ Opioid treatment of chronic pain is recognized as an acceptable and effective method, whereas opioids have the potential for abuse and addiction. ${ }^{[2]}$ As an opioid analgesic for parenteral administration, dextrozine has minimal side effects and low dependence, and has an agonistic and antagonistic effect on opioid receptors. It is a bridged aminotetrahydronaphthalene. ${ }^{[3,4]}$. Dezocine is a potent opioid receptor agonist-antagonist, which mainly produces analgesic effect by agonizing $\mathrm{k}$ receptors. It has strong analgesic effect, rapid absorption and distribution in human body, large apparent volume, long half-life and slow elimination. Its analgesic intensity, onset time and duration of action are comparable to morphine. Previous studies have shown that due to the morphine-like action of dezocine, some humanoid experimental animals can produce relatively equivalent or more effective analgesic effects than morphine in vivo and in humans. ${ }^{[5]}$ Previous studies have suggested that due to the partial agonist activity of dezocine on the $\mu$ opioid receptor, it causes fewer adverse reactions in clinical treatment. ${ }^{[6]}$ As a new anesthetic analgesic, dezocine is widely used in clinical practice, and a large number of randomized controlled trials have been conducted to study its efficacy and safety. However, there is currently no statistical evidence-based medical evidence to systematically validate the efficacy and safety of dezocine. Therefore, this study conducted a meta-analysis of the efficacy and safety of dezocine to control postoperative pain, and provided statistical guidance for the clinical application of dezocine.

\section{Methods}

\subsection{Search strategy}

We conducted a literature search to identify relevant available articles published from the databases of PubMed, Embase, The Cochrane Library and China National Knowledge Infrastructure (CNKI) up to April 29, 2019. Search terms included "dezocine", "postoperative pain", "anesthesia" ,"randomized controlled trials". A combination of subject terms and free words were used for the search. The two authors independently screened for eligibility for inclusion in the study and the third reviewer resolved the disagreements from an objective perspective.

\subsection{Selection criteria}

Inclusion articles satisfied the following criteria:

(1) Randomized controlled clinical trials to evaluate Dezocine as a treatment for anesthesia in patients; (2) with or without Dezocine compared with other anesthetics/placebo; (3) Data can be used for at least 1 or all of the following results: visual analogue Score (VAS), Ramsay sedation score, mean arterial pressure (MAP), heart rate (HR), Pulse Oxygen Saturation (SpO2) and the incidence of adverse events (AEs).

Exclusion criteria for the article include reviews, case reports, letters, editorials, and studies lacking the necessary data, and are not related to our research topics or are not randomized controlled clinical trials.

\subsection{Data extraction}

Three reviewers independently screened the report and extracted data from the included studies. The following data were collected: first author, year of publication, study design, number of patients, age(mean), sex(male/female)

, treatment regimen, intervention, drug dose, anesthesia and analgesia, and endpoint measures (Table 1).

\subsection{Outcome measures}

The outcome measures were VAS, Ramsay sedation score, MAP, HR, SpO2 and AEs. The mean arterial blood pressure, average heart rate, and pulse oxygen saturation at the different time points: end of surgery (T0), before extubation (T1), during extubation (T2) were compared. This meta-analysis follows the guidelines provided by the Preferred Reporting Items for Systematic Reviews and Meta-Analyses Report (PRISMA statement). [7]

\subsection{Data analysis}


The data analyses were performed using Computer Program Review Manager 5.3 (Copenhagen: The Nordic Cochrane Centre, The Cochrane Collaboration).

It is estimated that there is a certain degree of heterogeneity between the included RCTs, so the random effects model is used for analysis. Safety is assessed by summarizing the OR of the AEs. The efficacy of dezocine was assessed by comparing its VAS/Ramsay score/MAP/HR/SpO2 with placebo and the corresponding $95 \%$ confidence interval $(95 \% \mathrm{Cl})$. Heterogeneity was assessed using Chi 2 test and $\mathrm{I} 2$ statistics and published bias was assessed using funnel plot.

\section{Results}

\subsection{Search results and characteristics of patients in the included studies}

The PRISMA diagram of the study selection process and the reasons for exclusion is shown in Figure 1. Our search retrieved 1597 publications. 694 studies were excluded as duplicates and 889 were excluded because they did not meet the eligibility criteria in the initial selection. After reviewing the abstracts and full articles, 14 distinct trials were included in our analysis after removing the articles lacking necessary data and those utilizing insufficient follow-up periods. All studies were published in the last 8 years. 1820 patients were included in this analysis.

\subsection{Efficacy outcomes of Dezocine}

\subsubsection{1h/6h/24h Postoperative visual analogue score (VAS)}

A total of 6 studies compared the 1h/6h/24h VAS of dezocine and saline. The results showed that the analgesic effect of the $1 \mathrm{~h} / 6 \mathrm{~h}$ dezocine group was better than that of the saline group [MD=-1.37, 95\% Cl(-2.06囚-0.67), $\mathrm{P}=0.0001]$, [MD=-0.52, 95\% Cl (-1.04区0.01), $\mathrm{P}=0.05]$ (Fig. 2A B), 24h VAS group was not statistically significant (Fig. 2C)

\subsubsection{2h/8h Postoperative Ramsay sedation score}

A total of 5 studies compared the Ramsay sedation scores of dezocine and saline $2 \mathrm{~h} / 8 \mathrm{~h}$ after surgery. The results showed that the postoperative sedation effect of the $2 \mathrm{~h}$ dezocine group was better than that of the saline group [MD=1.21, $95 \% \mathrm{Cl}(0.67 \nabla 1.75), \mathrm{P}<0.0001]$ (Fig. $3 \mathrm{~A})$, the $8 \mathrm{~h}$ Ramsay sedation score was not statistically significant (Fig. 3B)

\subsection{Vital signs outcomes of Dezocine}

\subsubsection{T0/T1/T2 Mean arterial pressure (MAP)}

A total of 8 studies compared the mean arterial pressure (MAP) of T0/T1/T2 in dezocine and saline. The results showed that the MAP of the T1/T2 phase of the dezocine group was lower than that of the saline group [MD=-2.66, 95\%). $\mathrm{Cl}(-5.07 \sim-0.25), \mathrm{P}=0.03],[\mathrm{MD}=-4.53,95 \% \mathrm{Cl}(-6.17 \sim-2.89), \mathrm{P}<0.00001](\mathrm{Fig} .4 \mathrm{~B} \mathrm{C})$, the TO MAP group was not statistically significant. (Fig. 4A)

\subsubsection{T0/T1/T2 Heart rate (HR)}

A total of 8 studies compared the T0/T1/T2 heart rate (HR) of dezocine and saline. The results showed that the HR of the T0/T1 phase of the dezocine group was lower than that of the saline group [MD=-2.26, 95\% $\mathrm{Cl}(-4.32 \sim-0.21), \mathrm{P}=0.03]$, [MD $=-3.58,95 \% \mathrm{Cl}(-5.21 \bigotimes-1.96), \mathrm{P}<0.0001]$ (Fig. 5A B), T2 HR group was not statistically significant (Fig. 5C)

\subsubsection{T0/T1 Pulse Oxygen Saturation (Sp02)}

A total of 6 studies compared T0/T1 Pulse Oxygen Saturation (SpO2) between dezocine and saline. The results showed that SpO2 in the T0 phase of the dezocine group was lower than that in the saline group $[\mathrm{MD}=-0.90,95 \% \mathrm{Cl}(-1.77 \sim-0.03), \mathrm{P}=0.04]$ (Fig. $6 \mathrm{~A})$, the SpO2 of the T1 phase of the dezocine group was slightly higher than that of the saline group $[\mathrm{MD}=0.36,95 \% \mathrm{Cl}(0.02-0.71), \mathrm{P}=0.04]$ (Fig. 6B).

\subsection{Safety outcomes of Dezocine (AEs)}

A total of 11 studies compared the incidence of adverse events between dezocine and saline. The results showed that the adverse events in the dezocine group were lower than those in the saline group [OR=0.53,95\% $\mathrm{Cl}(0.39-0.71), \mathrm{P}<0.0001]$ (Fig. 7). In addition, taking into account the heterogeneity of the included studies, we used a funnel plot analysis, An additional funnel plot did not reveal apparent evidence of publication bias. (Fig. 8囚

\section{Discussion}

Recent technology advances in minimally invasive surgical procedures and postoperative anesthetic management and have resulted in reductions in morbidity, enhanced rehabilitation, and an earlier resumption of daily activities. ${ }^{[22]}$ With the improvement of surgical safety and the enhancement of anesthesia quality, the evaluation of restoration quality has become one of the significant end points of current mainstream research. ${ }^{[23]}$ Inappropriate management of postoperative pain and loss of control can lead to complications and affect long-term recovery, which is associated with continued progression of chronic pain and a reduction in the quality of life of patients ${ }^{[24,25]}$. Opioids are now widely used for postoperative analgesia after various types of surgery, such as sufentanil and morphine. ${ }^{[26,27]}$ However, opioid-related side effects and addiction can not be ignored, which prompted us to enthusiasm for the application of new anesthetics or combined drugs, reduce the clinical consumption of opioids, to the greatest extent to avoid adverse reactions and achieve encouraging postoperative analgesic efficacy. Dezocine is a $\mathrm{k}$ opioid receptor agonist and an opioid receptor antagonist. This is an effective opioid 


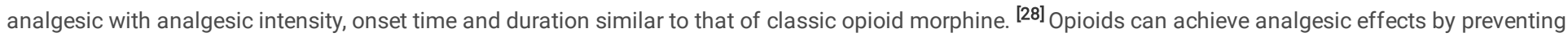
harmful stimulation in duced by central nervous impulses or by previously reducing central nervous system excitability, thereby reducing or eliminating central sensitization caused by injury. As an opioid receptor agonist-antagonist with more clinical use, dezocine mainly produces analgesic effect through agonistic $\mathrm{k}$ receptor, and achieves the goal of preemptive analgesia by peripheral sensitization and central sensitization inhibition, and has appropriate sedative effect, not easy to produce tolerance. In addition, because dezocine does not produce typical $\mu$ receptor dependence, it can relax gastrointestinal smooth muscle and reduce the incidence of nausea and vomiting; the occurrence of skin itching is also related to the excitability of $\mu$ receptor, after application of dezocine. The blockage of the body also reduces the incidence of skin itching and improves the quality of postoperative analgesia. Previous studies have demonstrated that dezocine can reduce postoperative pain and reduce adverse reactions such as postoperative nausea and vomiting, respiratory depression, dizziness, and urinary retention.

Our meta-analysis included 14 eligible RCT clinical studies with a total of 1820 patients. First, we systematically evaluated the visual analogue score (VAS) and the Ramsay sedation score. The results showed that dezocine had relatively superior sedative and analgesic effects. Secondly, we calculated the three vital signs of mean arterial pressure (MAP), heart rate (HR), and Pulse Oxygen Saturation (SpO2). The results showed that the application of dezocine could reduce postoperative MAP and HR. There was no significant correlation between the use of dezocine and SpO2. Then, we analyzed the incidence of adverse events, and the results showed that dezocine had fewer adverse events than the control group, suggesting that the safety of dezocine is better and more acceptable.

By analyzing the aggregated data, we observed a degree of heterogeneity in the experimental articles in this meta-analysis. The source of heterogeneity may be due to differences in the dose of dezocine used, or it may be due to differences in the patient's original chronic disease. To ensure the convincing objectivity of the analysis results, we use a random effects model to analyze the aggregated data. We used a funnel plot to evaluate publication bias in the included studies and found that publication bias was not one of the factors that contributed to heterogeneity.

Critically, our research has some inevitable limitations. First, there are differences in the types of surgery and disease types involved in the included RCTs, which may lead to partial selectivity bias. Second, due to the limited number of RCTs currently available for dezocine, there is a relative irreversible heterogeneity between the included RCTs, which affects the reliability of some statistical results. At present, multi-center clinical trials for dezocine are being carried out all over the world. We are waiting for new data and results to provide further theoretical support for better clinical application of dezocine.

\section{Conclusions}

According to the meta-analysis of the existing RCT studies, the use of dezocine for postoperative analgesia can relieve postoperative pain and reduce the occurrence of adverse events. Therefore, Dezocine is suggested to be a potentially useful adjunctive anesthesia analgesic for the management of postoperative pain.

\section{Abbreviations}

RCT, Randomized controlled trials. PRFA, Percutaneous radiofrequency ablation. PCA, Patient controlled analgesia. PICA, Patient controlled intravenousanalgesia. NR, Not related. GA, General anesthesia. RA, Regional anesthesia. NRS, Numerical rating scale. VAS, Visual analogue score. ABP, Arterial blood pressure. MAP, Mean arterial pressure. HR, Heart rate. SpO2, Pulse oxygen saturation. RR, Respiratory rate. VRS, Verbal rating scale. MMSE, Mini-mental state examination.

\section{Declarations}

\section{Availability of data and materials}

The analyzed datasets generated during the study are available from the corresponding author on reasonable request.

\section{ACKNOWLEDGMENTS}

This work was supported by National Natural Science Foundation of China (grant number: 81772713, 81372752, 81472411, 81101932), Natural Science Foundation of Shandong Province (grant number: ZR2016HM81).

\section{Author Contributions}

Haitao Niu was lead investigator and responsible for the overall design and leadership of the study as well as supervision of project staff, study inclusion, data analysis and manuscript development. Fengxi Hao and Zhongyuan Fan conducted the screening process (study inclusion), data extraction/analyses, and contributed to drafting of manuscript. Feng Chen conducted the literature searches. Haichen Chu and rest authors participated in designing the study and contributed to drafting the manuscript. All authors read and approved the final manuscript.

\section{Ethics declarations}


Not required owing to the design of the research (systematic review).

\section{Consent for publication}

Not applicable.

\section{Competing interests}

The authors declare that they have no conflict of interest.

\section{References}

1. Mccarthy G C, Megalla S A, Habib A S. Impact of Intravenous Lidocaine Infusion on Postoperative Analgesia and Recovery from Surgery. Drugs. 2010;70(9):1149-1163.

2. Chou R, Fanciullo G J, Fine P G, et al. Clinical Guidelines for the Use of Chronic Opioid Therapy in Chronic Noncancer Pain. The journal of pain: official journal of the American Pain Society. 2009;10(2):113-130.

3. Gharagozlou P, Hashemi E, Delorey T M, et al. Pharmacological profiles of opioid ligands at Kappa opioid receptors. BMC Pharmacology. 2006;6.

4. Fischer B D, Miller L L, Henry F E, et al. Increased efficacy of $\mu$-opioid agonist-induced antinociception by metabotropic glutamate receptor antagonists in C57BL/6 mice: comparison with (-)-6-phosphonomethyl-deca-hydroisoquinoline-3-carboxylic acid (LY235959). Psychopharmacology. 2008;198(2):271278.

5. Malis J L, Rosenthale M E, Gluckman M I. Animal pharmacology of Wy-16,225, a new analgesic agent. Journal of Pharmacology \& Experimental Therapeutics. 1975;194(3):488-98.

6. Wang Y H, Chai J R, Xu X J, et al. Pharmacological Characterization of Dezocine, a Potent Analgesic Acting as a $\mathrm{k}$ Partial Agonist and $\mu$ Partial Agonist. Scientific Reports. 2018;8(1).

7. Moher D, Liberati A, Tetzlaff J, et al. Preferred reporting items for systematic reviews and meta-analyses: the PRISMA statement. 2009;339:b2535.

8. Zhou L, Zhang Y, Sun H, et al. Effect of preemptive dezocine before general anesthesia on postoperative analgesia in patients undergoing laparoscopic cholecystectomy: A prospective observational study. Medicine (Baltimore). 2018;97(39):e12533

9. Jia Z, Hao H, Huang M, et al. Influence of dexmedetomidine to cognitive function during recovery period for children with general anesthesia. European Review for Medical \& Pharmacological Sciences. 2017;21(5):1106.

10. Yao Z Y, Jia Z, Xie Y H, et al. Analgesic effect of dezocine in different doses on elderly patients undergoing abdominal operation under general anesthesia and its influence on stress response to postoperative tracheal extubation. European Review for Medical \& Pharmacological Sciences. 2017;21(22):5223.

11. Zhou M, Wang L, Wu C, et al. Efficacy and safety of different doses of dezocine for preemptive analgesia in gynecological laparoscopic surgeries: A prospective, double blind and randomized controlled clinical trial. International Journal of Surgery. 2017;S1743919117314012.

12. Yao Y Q, Liu Y H, Fan Z Y, et al. Random clinical study about application value of oxycodone in radiofrequency ablation of hepatocellular carcinoma]. Chinese journal of surgery. 2016;54(10):772.

13. Xiang Y, Ye W, Sun N, et al. Analgesic and Sedative Effects of Dezocine and Midazolam During Vitrectomy. Current Eye Research. 2016:1-5.

14. Li S, Min S, Wu B, et al. Application of patient-controlled intravenous analgesia of dezocine combined with sufentanil in burn patients after surgery]. Chinese journal of burns. 2015;31(1):48-51.

15. He L, Ding Y, Chen $\mathrm{H}$, et al. Dezocine pretreatment prevents myoclonus induced by etomidate: a randomized, double-blinded controlled trial. Journal of Anesthesia. 2015;29(1):143-145.

16. Lu Z, Fang J, Zhu J, et al. Intravenous dezocine pretreatment reduces the incidence and intensity of myoclonus induced by etomidate. Journal of Anesthesia. 2014;28(6):944-947.

17. Wu L, Dong Y P, Sun L, et al. Low Concentration of Dezocine in Combination With Morphine Enhance the Postoperative Analgesia for Thoracotomy. $J$ Cardiothorac Vasc Anesth. 2015;29(4):950-954.

18. Jiao L, Liu RC. Effects of dezocine on postoperative sore throat after maxillofacial procedures: a comparison with flurbiprofen axetil. Journal of Peking University (Health Sciences). 2014;46(1):104-6

19. Liu X S, Xu G H, Shen Q Y, et al. Dezocine prevents sufentanil-induced cough during general anesthesia induction: A randomized controlled trial. Pharmacological Reports. 2015;67(1):52-55.

20. Zhang Y, Lu Y, Wong G T C, et al. Prevention of injection pain due to propofol by dezocine: A comparison with lidocaine. Indian Journal of Pharmacology. 2013;45(6):619.

21. Sun Z T, Yang C Y, Cui Z, et al. Effect of intravenous dezocine on fentanyl-induced cough during general anesthesia induction: a double-blinded, prospective, randomized, controlled trial. Journal of Anesthesia. 2011;25(6):860-863.

22. Johnson A. Laparoscopic surgery. Archivos Españoles De Urología. 1997;349(9052):631.

23. Murphy G S, Szokol J W, Greenberg S B, et al. Preoperative dexamethasone enhances quality of recovery after laparoscopic cholecystectomy: effect on inhospital and postdischarge recovery outcomes. 2011;114(114):882-890.

24. Kehlet H, Holte K. Effect of postoperative analgesia on surgical outcome. BJA British Journal of Anaesthesia. 2001;87(1):62-72.

25. Kehler H. Persistent postsurgical pain : risk factors and prevention. 2006;367(9522):1618-1625. 
26. Movafegh A, Shoeibi G, Ansari M, et al. Naloxone infusion and post-hysterectomy morphine consumption: A double-blind, placebo-controlled study. Acta Anaesthesiologica Scandinavica. 2012;56(10):1241-1249.

27. George R B, Mckeen D M, Andreou P, et al. A randomized placebo-controlled trial of two doses of pregabalin for postoperative analgesia in patients undergoing abdominal hysterectomy. Can J Anaesth. 2014;61(6):551-557.

28. Chengmao Z, Yuting Y, Yu Z, et al. Effects of dezocine on prevention of propofol injection pain: a meta-analysis. Journal of Pain Research. 2017;10:13691375 .

\section{Tables}

Table 1. Characteristics of the included studies in the meta-analysis.

\begin{tabular}{|c|c|c|c|c|c|c|c|c|c|}
\hline Study & Year & $\begin{array}{l}\text { Study } \\
\text { design }\end{array}$ & $\begin{array}{l}\text { Num. of } \\
\text { patients } \\
\text { D/S }\end{array}$ & Age(mean) & Sex(male/female) & treatment regimen & Intervention & Dosage & Analgesia \\
\hline $\begin{array}{l}\text { Zhou } \\
\text { et al }{ }^{8}\end{array}$ & 2018 & $\mathrm{RCT}$ & 80 & 51.5 & $43 / 37$ & $\begin{array}{l}\text { laparoscopic } \\
\text { cholecystectomy }\end{array}$ & $\begin{array}{l}\text { Dezocine vs } \\
\text { Saline }\end{array}$ & $0.15 \mathrm{mg} / \mathrm{kg}$ & PCA(fentani \\
\hline $\begin{array}{l}\text { Jia et } \\
\text { al }^{9}\end{array}$ & 2017 & $\mathrm{RCT}$ & 93 & 13.6 & $54 / 39$ & $\begin{array}{l}\text { adenoidectomy or } \\
\text { adenotonsillectomy }\end{array}$ & $\begin{array}{l}\text { Dezocine vs } \\
\text { Dexmedetomidine } \\
\text { vs Saline }\end{array}$ & $0.1 \mathrm{mg} / \mathrm{kg}$ & PCA(fentani \\
\hline $\begin{array}{l}\text { Yao } \\
\text { et al } \\
10\end{array}$ & 2017 & RCT & 76 & 63.2 & $38 / 38$ & $\begin{array}{l}\text { abdominal } \\
\text { operation }\end{array}$ & $\begin{array}{l}\text { Dezocine vs } \\
\text { Saline }\end{array}$ & $0.05 / 0.1 / 0.15 \mathrm{mg} / \mathrm{kg}$ & PCIA(fentan \\
\hline $\begin{array}{l}\text { Zhou } \\
\text { et al } \\
11\end{array}$ & 2017 & $\mathrm{RCT}$ & 390 & 37.8 & $0 / 390$ & $\begin{array}{l}\text { Gynecological } \\
\text { Laparoscopic } \\
\text { Surgeries }\end{array}$ & $\begin{array}{l}\text { Dezocine vs } \\
\text { Saline }\end{array}$ & $0.1 / 0.15 / 0.2 \mathrm{mg} / \mathrm{kg}$ & PCA(fentani \\
\hline $\begin{array}{l}\text { Yao } \\
\text { et al } \\
12\end{array}$ & 2016 & $\mathrm{RCT}$ & 60 & 57 & $24 / 36$ & $\begin{array}{l}\text { PRFA in } \\
\text { hepatocellular } \\
\text { carcinoma }\end{array}$ & $\begin{array}{l}\text { Dezocine vs } \\
\text { Fentanyl vs } \\
\text { Oxycodone }\end{array}$ & $0.1 \mathrm{mg} / \mathrm{kg}$ & PCA(fentani \\
\hline $\begin{array}{l}\text { Xiang } \\
\text { et al } \\
13\end{array}$ & 2016 & RCT & 160 & 43.8 & $77 / 83$ & Vitrectomy & $\begin{array}{l}\text { Dezocine vs } \\
\text { Midazolam vs } \\
\text { Saline }\end{array}$ & $0.1 \mathrm{mg} / \mathrm{kg}$ & PCA(lignoca \\
\hline $\begin{array}{l}\text { Li et } \\
\text { al }^{14}\end{array}$ & 2015 & $\mathrm{RCT}$ & 60 & 41.5 & $36 / 24$ & $\begin{array}{l}\text { autologous skin } \\
\text { grafting }\end{array}$ & $\begin{array}{l}\text { Dezocine vs } \\
\text { Fentanyl vs } \\
\text { Saline }\end{array}$ & $0.25 \mathrm{mg} / \mathrm{kg}$ & PCIA(fentan \\
\hline $\begin{array}{l}\text { He et } \\
\text { al }^{15}\end{array}$ & 2014 & $\mathrm{RCT}$ & 108 & 42.5 & $54 / 54$ & $\begin{array}{l}\text { myoclonus induced } \\
\text { by etomidate }\end{array}$ & $\begin{array}{l}\text { Dezocine vs } \\
\text { Saline }\end{array}$ & $0.1 \mathrm{mg} / \mathrm{kg}$ & PCIA(etomid \\
\hline $\begin{array}{l}\text { Lu et } \\
\mathrm{al}^{16}\end{array}$ & 2014 & $\mathrm{RCT}$ & 80 & 37.2 & $40 / 40$ & $\begin{array}{l}\text { myoclonus induced } \\
\text { by etomidate }\end{array}$ & $\begin{array}{l}\text { Dezocine vs } \\
\text { Saline }\end{array}$ & $0.1 \mathrm{mg} / \mathrm{kg}$ & PCIA(etomid \\
\hline $\begin{array}{l}\text { Wu et } \\
\text { al }^{17}\end{array}$ & 2014 & $\mathrm{RCT}$ & 58 & 52.9 & $26 / 32$ & thoracotomywere & $\begin{array}{l}\text { Dezocine vs } \\
\text { Morphine vs } \\
\text { Saline }\end{array}$ & $0.1 \mathrm{mg} / \mathrm{kg}$ & PCIA(morph \\
\hline $\begin{array}{l}\text { Liang } \\
\text { et al } \\
18\end{array}$ & 2014 & $\mathrm{RCT}$ & 90 & 41.9 & $44 / 46$ & $\begin{array}{l}\text { Maxillofacial } \\
\text { surgery }\end{array}$ & $\begin{array}{l}\text { Dezocine vs } \\
\text { Flurbiprofen vs } \\
\text { Saline }\end{array}$ & $0.1 \mathrm{mg} / \mathrm{kg}$ & PCA(fentani \\
\hline $\begin{array}{l}\text { Liu et } \\
\text { al }^{19}\end{array}$ & 2014 & $\mathrm{RCT}$ & 370 & 52.5 & $190 / 180$ & $\begin{array}{l}\text { fentanyl-induced } \\
\text { cough }\end{array}$ & $\begin{array}{l}\text { Dezocine vs } \\
\text { Saline }\end{array}$ & $0.1 \mathrm{mg} / \mathrm{kg}$ & PCA(fentani \\
\hline $\begin{array}{l}\text { Lu et } \\
\text { al } 20\end{array}$ & 2013 & RCT & 75 & 48 & $36 / 39$ & elective surgery & $\begin{array}{l}\text { Dezocine vs } \\
\text { Lidocaine vs } \\
\text { Saline }\end{array}$ & $2 \mathrm{mg} / 2 \mathrm{ml}$ & NR \\
\hline $\begin{array}{l}\text { Sun } \\
\text { et al } \\
21\end{array}$ & 2011 & RCT & 120 & 47.4 & $68 / 52$ & $\begin{array}{l}\text { fentanyl-induced } \\
\text { cough }\end{array}$ & $\begin{array}{l}\text { Dezocine vs } \\
\text { Saline }\end{array}$ & $0.1 \mathrm{mg} / \mathrm{kg}$ & PCA(fentani \\
\hline
\end{tabular}

Abbreviation: RCT, Randomized controlled trials. PRFA, Percutaneous radiofrequency ablation. PCA, Patient controlled analgesia. PICA, Patient controlled intr: anesthesia. RA, Regional anesthesia. NRS, Numerical rating scale. VAS, Visual analogue score. ABP, Arterial blood pressure. MAP, Mean arterial pressure. HR, I Respiratory rate. VRS, Verbal rating scale. MMSE, Mini-mental state examination. 


\section{Supplementary Files}

This is a list of supplementary files associated with this preprint. Click to download.

- PRISMAChecklist.doc

- PRISMAFlowDiagram.doc 